\title{
O Desenho como Ferramenta Projetual no Design de Moda
}

\author{
Drawing as a Project Tool in Fashion Design
}

\author{
HATADANI, Paula da Silva; Mestre; Universidade Estadual Paulista \\ Julio de Mesquita Filho - UNESP \\ paulahatadani@yahoo.com.br \\ MENEZES, Marizilda dos Santos; Doutora; Universidade Estadual Paulista \\ Júlio de Mesquita Filho - UNESP \\ marizil@faac.unesp.br
}

\begin{abstract}
Resumo
Este artigo pretende alocar as diferentes linguagens do desenho nas etapas do processo de desenvolvimento de produtos do vestuário. Para tanto, baseia-se nas diretrizes metodológicas para o processo projetual de design de moda apresentada por Montemezzo (2003). Inicialmente, realiza um levantamento bibliográfico acerca dos tipos de linguagem de desenho de moda existentes. Depois, analisa as especificidades de cada linguagem e as ajusta às etapas apresentadas pela autora citada.
\end{abstract}

Palavras-chave: Design de moda; Desenho de Moda; Moda. Representação gráfica.

\begin{abstract}
This article intends to allocate the different fashion drawing languages used in the development stages of fashion design. To do so, it is based on the methodological guidelines for fashion design presented by Montemezzo (2003). Initially, presents a bibliographic study about the types of fashion drawing languages. Then analyzes the specificities of each language and adjust them to the steps presented by the author cited.
\end{abstract}

Keywords: Fashion Desig; Fashion Design; Fashion; Graphic representation.

\section{Introdução}

A relevância do setor têxtil e de vestuário para a economia do Brasil é notável e crescente. Segundo dados da ABIT (ASSOCIAÇÃO BRASILEIRA DA INDÚSTRIA TÊXTIL E CONFECÇÃO, 2010), o setor é o quinto maior do mundo, compreendendo cerca de 30.000 empresas registradas, cujo faturamento representa 17,5\% do PIB da indústria de transformação e 3,5\% do PIB brasileiro.

Neste panorama, observa-se que a solidificação e a profissionalização do setor dependem de ações voltadas para o gerenciamento e o planejamento de todas as etapas produtivas, entre elas, o desenvolvimento de produtos. Neste sentido, tornam-se cada vez mais evidentes as intenções da indústria e da academia em estreitar as relações entre a moda e o design, visto que é crescente a demanda por profissionais capazes de atuar de forma sistêmica, articulando de forma interdisciplinar todas as questões relacionadas ao mercado, à produção, à cultura e à tecnologia (PIRES, 2008).

Para Montemezzo (2003), esta articulação pode ser facilitada pela utilização de 
Paula da Silva Hatadani; Marizilda dos Santos Menezes

diretrizes metodológicas, que podem contribuir tanto para a organização do processo criativo quanto para a capacidade de síntese e direcionamento de critérios para decisões projetuais. A autora ressalta que, deste modo, o processo criativo no design de moda afasta-se do da idéia romântica da "inspiração", ou seja, da visão do criador como "gênio", partindo para uma atuação mais profissional, técnica e, portanto, real.

Na tabela abaixo (Tabela 1), Montemezzo (2003) sintetiza o percurso do desenvolvimento de produtos de moda, em sintonia com as fases delimitadas por Lobach (2001) para projetos de design:

Tabela 1- Etapas e ações no desenvolvimento de produtos de moda

\begin{tabular}{|c|c|}
\hline Etapas & Ações \\
\hline \multirow{5}{*}{ Planejamento } & Petcepşào do mercado e descoberta de opertunidades. \\
\hline & Analies expectativas e histónico comercial da empiesa. \\
\hline & Ideias p/ produtos / Identíficaşào do problema de Design. \\
\hline & $\begin{array}{l}\text { Definição de estratígias de marketing, desenvolvimento, produç̧o, distrubúçio e } \\
\text { vendas. }\end{array}$ \\
\hline & Definiçào do cronograma. \\
\hline \multirow{4}{*}{ Especificaçào do Projeto } & Anälise e definição do problema de Design (diretrizes). \\
\hline & Sintese do universo do consumidor (fisico e psicológgeo). \\
\hline & Pesquisa de conteúdo de moda (tendèncias). \\
\hline & Delimita saio do projeto (objetivos). \\
\hline \multirow[b]{2}{*}{ Delimitaçào Conceitual } & 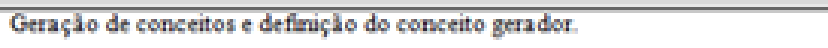 \\
\hline & Definiço de principios funcionais e de entilo. \\
\hline \multirow[t]{2}{*}{ Geraçào de Alternativas } & $\begin{array}{l}\text { Geração de altemativas de solução do problema. } \\
\text { (esboços desenhos, estudos de modelos). }\end{array}$ \\
\hline & Definiçōes de configuração, materiais e tecnologass. \\
\hline \multirow{5}{*}{$\begin{array}{l}\text { Avaliaçào e } \\
\text { Elaboraçào }\end{array}$} & Seleşio da(t) mether (es) altemativa( $(i)$. \\
\hline & $\begin{array}{l}\text { Detallhamento de configuraşio. } \\
\text { (desenho tienico). }\end{array}$ \\
\hline & Desenvolvimento de ficha técnics, modelagem e protótipe. \\
\hline & Testes ergonómicos e de usabilisdade. \\
\hline & Correçdes/a dequaş̧es. \\
\hline \multirow{8}{*}{ Realização } & Avaliaçōes técnicas e comerciais apuradas. \\
\hline & $\begin{array}{l}\text { Conreçōes a dequaç̧̄es. } \\
\text { Graduaçāo da modelagem. }\end{array}$ \\
\hline & $\begin{array}{l}\text { Confeç̧io de ficha técrica definitiva e peça-puloto. (aprovaçdo técrica e } \\
\text { comercial do(s) produto(s)). }\end{array}$ \\
\hline & Aquisiçio de maténa -prima e aviamentos. \\
\hline & Orientaçào dos setores de produção e vendas. \\
\hline & Defrnçio de embalagens e matenal de divulgasio. \\
\hline & Produça. \\
\hline & Lançamento do(s) ptoduto(s). \\
\hline
\end{tabular}

Fonte: Montemezzo (2003, p.62)

Analisando a tabela, verifica-se que o trabalho executado no desenvolvimento de produtos de moda abrange atividades que exigem do profissional diferentes tipos de competências, sejam elas científicas (nas etapas que envolvem a pesquisa), técnicas (nas etapas de elaboração e realização) ou, ainda, artísticas, (nas etapas em que são fundamentais a expressão, linguagem visual e processo criativo).

As competências científicas garantem que o profissional será capaz de investigar e 
O Desenho como Ferramenta Projetual no Design de Moda

interpretar fundamentos teóricos para a compreensão do contexto histórico, sociocultural, simbólico e mercadológico em que atua. Já as competências técnicas viabilizam a aplicação destes fundamentos.

Já a última competência, a artística, diz respeito à expressividade criativa, ou seja, à capacidade de registrar e transmitir aquilo que se pensa, cria e projeta. Pode-se dizer que esta competência se materializa por meio da utilização de ferramentas específicas que o designer precisa conhecer e dominar, tais como o desenho, objeto de estudo do presente trabalho ${ }^{1}$.

Nota-se que o desenho aparece na tabela em duas das seis etapas definidas pela autora: na "Geração de alternativas" (com a nomenclatura "esboços/desenhos"), e na "Avaliação e Elaboração" (com a nomenclatura "desenhos técnicos").

Desta forma, a fim de evidenciar a importância da ferramenta "desenho" para a organização dos processos criativos e execução dos processos produtivos, este artigo realiza um levantamento bibliográfico acerca das diferentes linguagens do desenho de moda e detalha as suas especificidades, com o objetivo de alocá-las nas etapas apresentadas acima.

\section{Representação gráfica no Design de moda}

Segundo a definição de Ferreira (1995, p.210), o desenho é uma "representação de formas sobre uma superfície através de linhas, pontos e manchas, com objetivo lúdico, artístico ou técnico", ou, ainda, como "delineamento, esboço, elaboração". Já Riegelman (2006a), afirma que o desenho é uma linguagem que possibilita a expressão e comunicação visual de idéias, afimação complementada por Derdik (2007, p.35), que o descreve como "representações gráficas que se mostram como um meio possível de o artista armazenar reflexões, dúvidas, problemas ou possíveis soluções".

O desenho pode possuir formas diferentes de linguagem: há o desenho artístico, que se caracteriza por uma maior liberdade de criação e subjetividade; e o desenho técnico, 0 qual, segundo Bachmann e Forberg (1970, apud IZIDORO, 2009), tem possível origem ainda nos tempos primitivos, quando se realizavam projetos de monumentos de grande porte. Tais desenhos objetivam a comunicação de idéias para posterior materialização de um objeto, artefato ou construção.

A capacidade de "ver" e posteriormente "transmitir" aquilo que se vê é de fundamental importância para os profissionais do design. Isto porque, em projetos de produtos, o desenho não é, absolutamente, um fim em si mesmo, ou seja, não tem caráter artístico, mas deve ser utilizado como um canal, pelo qual as idéias do profissional tornam-se visíveis e podem ser discutidas, repensadas e materializadas. Deste modo, é importante destacar que o designer precisa tanto comunicar as idéias que ainda estão em sua mente, quanto representar aquilo que já foi projetado.

Para Riegelman (2006a), são dois os motivos pelos quais os desenhos de moda são realizados: Primeiro, para ilustrar de que maneiras as roupas que já existem podem ser modificadas pela posição, luz, estilo de cabelo, tom de pele, acessórios e outras variáveis neste propósito, o desenho funcionaria no sentido de comunicar informações subjetivas sobre o produto, por exemplo, a que público se destina, em que ocasião pode ser usado, qual a sensação que o produto provoca, entre outros. Em segundo lugar, para projetar novas vestimentas e acessórios - neste sentido, o desenho é visto como ferramenta de concepção de produtos, com o objetivo de comunicar formas, texturas, acabamentos, entre outros detalhamentos, para algo que ainda não foi concretizado.

Projética Revista Científica de Design I Universidade Estadual de Londrina I V.2 I N.1 I Junho 2011 
Paula da Silva Hatadani; Marizilda dos Santos Menezes

Outros autores, tais como Jones (2005), Blackman (2007), Morris (2006), Gragnato (2007), Suono (2007) e Duarte (2010), aprofundam ainda mais estas questões, explicitando com outros detalhes cada um dos objetivos do desenho de moda. Apesar de nem sempre utilizarem a mesma nomenclatura para os tipos de desenho, ou mesmo que às vezes os conceitos se misturem, pode-se dizer que concordam e se complementam em diversos pontos.

Neste trabalho serão esclarecidas as linguagens de desenho citadas pelos autores acima, algumas vezes alterando a nomenclatura utilizada por eles, na tentativa de traduzir e agrupar as colocações de todas as publicações. Tais linguagens são: o desenho de esboço; o desenho de estilo; e o desenho técnico de vestuário, que serão detalhadas a seguir.

\section{Desenho de esboço}

O esboço caracteriza-se como um desenho ágil, realizado à mão, apenas com papel e lápis. Por meio dele, o designer consegue reproduzir todos os seus pensamentos, sem barreiras de restrição, assim como num brainstorming. Idéias equivocadas misturam-se a boas idéias, mas isto não é um problema neste momento, visto que esta linguagem permite que as modificações necessárias sejam realizadas continuamente e de forma bastante rápida.

Cabe ressaltar que os objetivos do desenho de esboço não permitem a preocupação e o compromisso com a representação dos pormenores dos produtos. Porém, apesar desta característica informal, a qualidade deste desenho depende de algumas variáveis imprescindíveis para sua construção, tais como proporção, simplificação e traçado (SUONO, 2007).

O esboço construído de forma desproporcional acaba tendo pouca utilidade na comunicação, pois descaracteriza as informações representadas no desenho, comprometendo sua interpretação. A simplificação também se torna prioridade na construção de um bom esboço de projeto. Isso porque o uso de elementos gráficos desnecessários pode dificultar, significativamente, a compreensão das informações gráficas do desenho (SUONO, 2007, p.29).

De acordo com Morris (2006), o corpo humano pode ou não ser representado no esboço, assim como aviamentos e acabamentos. Estes detalhamentos devem ser representados apenas quando essenciais, como pode ser visto na Figura 1:

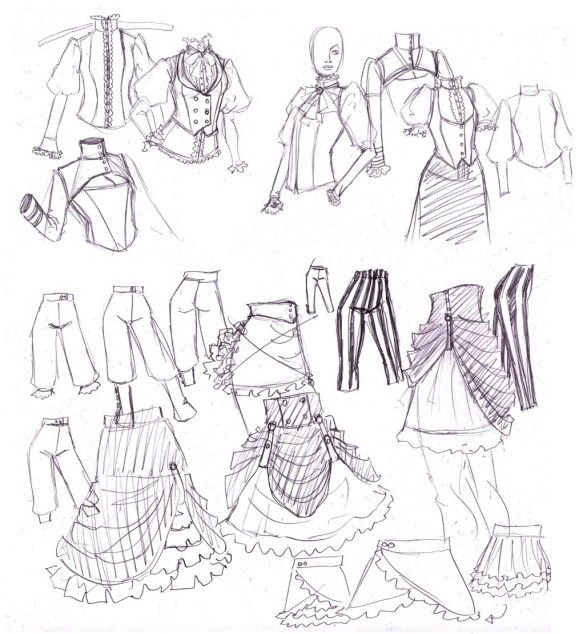

Figura 1- Desenhos de esboços para produtos de moda

Fonte: Fashion Sketches (2011) 
O Desenho como Ferramenta Projetual no Design de Moda

Analisando a figura, pode-se perceber que os desenhos foram realizados de forma rápida, pois os elementos aparecem na página de forma aleatória e muitas vezes se sobrepõem. Além disto, os traços são soltos e imprecisos. Algumas alternativas são reformuladas e redesenhadas com dispositivos diferentes, enquanto outras parecem ter sido bastante equivocadas, pois o autor nem sequer quis levar a idéia adiante (como na saia com um " $x$ " sobre ela). Verifica-se também que, embora tenha sido realizado de forma descontraída, o autor possui um bom domínio das proporções do corpo humano e de panejamento, e seu traçado é firme e bastante objetivo. Os detalhamentos essenciais para a compreensão da peça ficam evidentes (como caimento de tecidos, botões e martingales), porém, detalhes como acabamentos internos, forros ou dispositivos de abertura não foram representados.

Na tabela proposta por Montemezzo (2003) o desenho de esboço é a primeira das linguagens de representação gráfica a aparecer no processo de desenvolvimento de produtos de moda, na fase de "Geração de Alternativas". Isto porque este tipo de desenho possibilita a rapidez de expressão das idéias, ao mesmo tempo em que possui um baixo custo, configurandose como a ferramenta ideal para esta fase projetual, que tem como objetivo a busca por solução de problemas.

Após a fase de geração de alternativas, quando o designer julgar que possui idéias suficientes registradas, deverá selecionar os esboços que melhor traduzem as soluções para o que projeta. Estas alternativas escolhidas passarão por uma segunda "triagem": o desenho de estilo.

\section{Desenho de estilo}

O desenho de estilo se assemelha em muitos aspectos ao desenho de esboço, porém algumas diferenças citadas pelos autores estudados não permitem que sejam confundidos.

Assim como o esboço, o desenho de estilo está diretamente associado à representação de uma idéia a partir do ato de desenhar. São também representações rápidas, mais frequentemente realizadas com técnicas manuais, cuja função é possibilitar a junção do fazer e do pensar o produto em termos projetuais. Por meio dele, o designer registra idéias, estuda a coerência e a viabilidade do produto. Mas, diferentemente do esboço, é por meio do desenho de estilo que o designer comunica sua intenção a terceiros, apresentando suas idéias às pessoas com poder de decisão sobre a fabricação dos produtos (GRAGNATO, 2008; MORRIS, 2006). Assim, este tipo de representação é mais facilmente entendido como um "refinamento" das representações que foram previamente realizadas por meio do esboço.

No desenho de estilo a figura humana é quase sempre representada, pois o caimento do produto sobre o corpo é informação indispensável. A representação de volumes, formas, cores, texturas e detalhamentos também devem acontecer da maneira mais fiel à realidade quanto for possível, pois ele orientará decisões importantes quanto à adequação da coleção (conceito, público-alvo), custos (tecidos, aviamentos) e viabilidade técnico-produtiva (acabamentos, custos de produção) (Figura 2): 


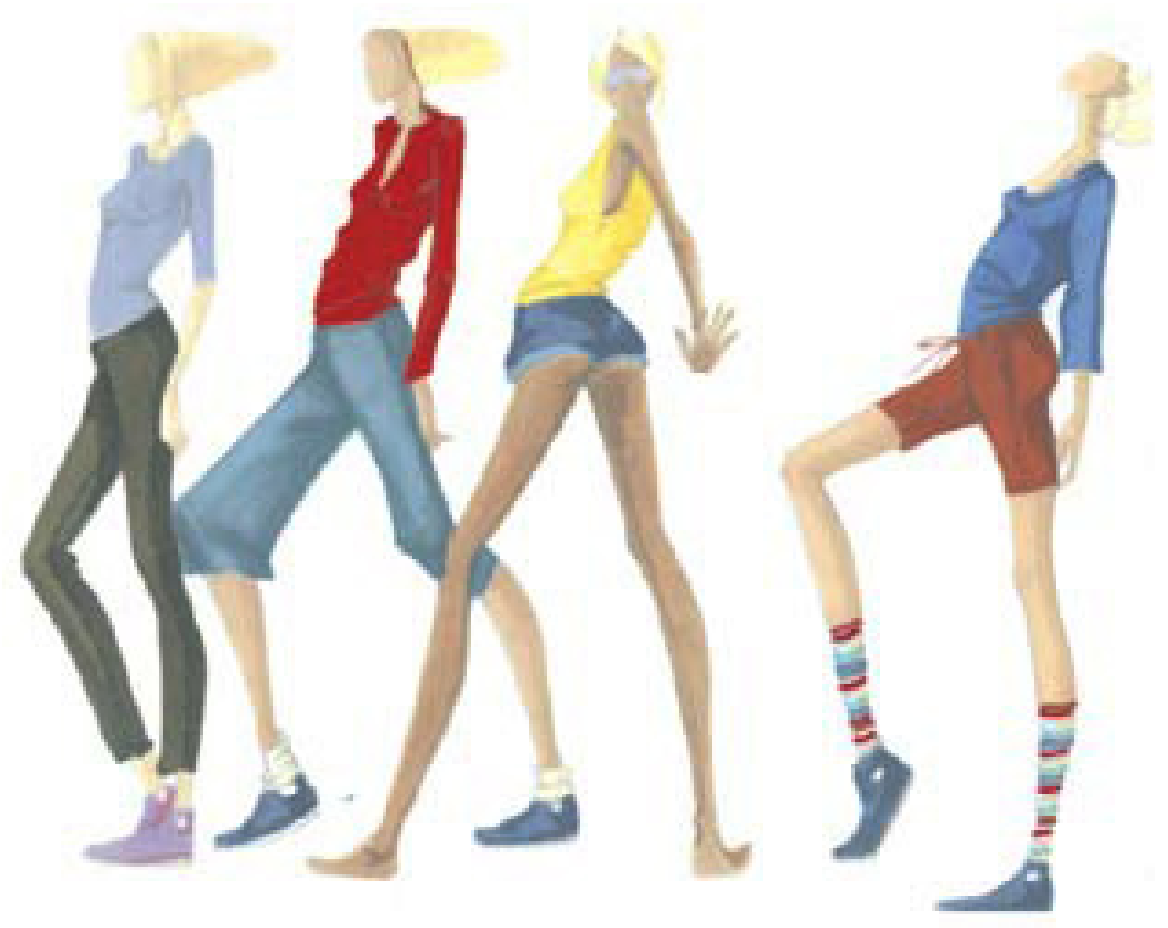

Figura 2 -Croquis femininos Fonte: Riegelman (2006b)

Quanto mais fiel à realidade o croqui, maior a probabilidade das idéias do designer serem aprovadas (RIEGELMAN, 2006a; GRAGNATO, 2007). Contudo, Jones (2005) afirma que o designer deve registrar de forma suficiente detalhes e estruturas, sem complicar demais o trabalho. O realismo deve ser usado de maneira parcimoniosa, pois o tempo é um importante limitador em empresas de confecção.

Assim como a representação de formas e estruturas, o corpo humano deve também ser mostrado com as suas proporções reais, a fim de não "enganar" o leitor no entendimento das peças. No entanto, é muito comum encontrar croquis em que algumas proporções são distorcidas e estilizadas, seja para evidenciar melhor os detalhamentos das peças, seja para tornar o corpo adaptado aos padrões de beleza vigente na época (BLACKMAN (2007); MORRIS (2006); JONES (2005).

Notipo médio de corpo feminino, o tamanho da cabeça corresponde aproximadamente a à altura dividida por sete e meio. No desenho de moda o divisor cresce para oito e meio a nove. O comprimento das pernas é exagerado em relação ao do tronco. Como a ênfase é na roupa, a figura é um pouco alongada, não só como efeito de elegância mas também com o intuito de deixar espaço para mostrar detalhes como bolsos e pespontos (JONES, 2005, p.90)

Segundo Morris (2006) e Riegelman (2006a), não há problemas em utilizar-se destas estilizações no desenho de croquis. No entanto, deve-se atentar para o fato de que estas distorções não devem ocorrer de forma que se modifique demais a figura, a ponto de se perderem as proporções básicas do corpo humano, e consequentemente das peças sobre ele representadas. Elas devem ser mantidas, de forma que o produto cubra-o obedecendo aos seus volumes, formas e articulações de forma harmônica, conforme mostra a Figura 3: 


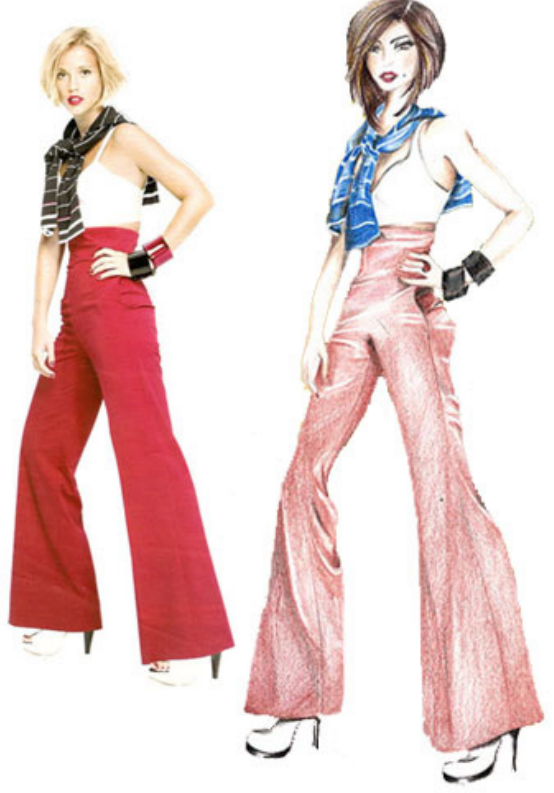

Figura 3- Foto e croqui com proporções alongadas

Fonte: Croquis ilustrados (2011)

No desenho anterior a figura humana foi alongada em cerca de uma cabeça. No entanto, esta diferença não prejudica o entendimento das proporções do produto, além de ajudar a enfatizar o comprimento mínimo da saia e os detalhamentos da blusa e do cinto.

Mas no desenho de estilo, o corpo humano, além de servir como base do produto de moda no sentido funcional, pode também traduzir características de personalidade do públicoalvo e do "espírito" da coleção, tanto por meio da estilização da figura como pelas técnicas de representação utilizadas, como pode ser visto no comparativo das Figuras 4 e 5:
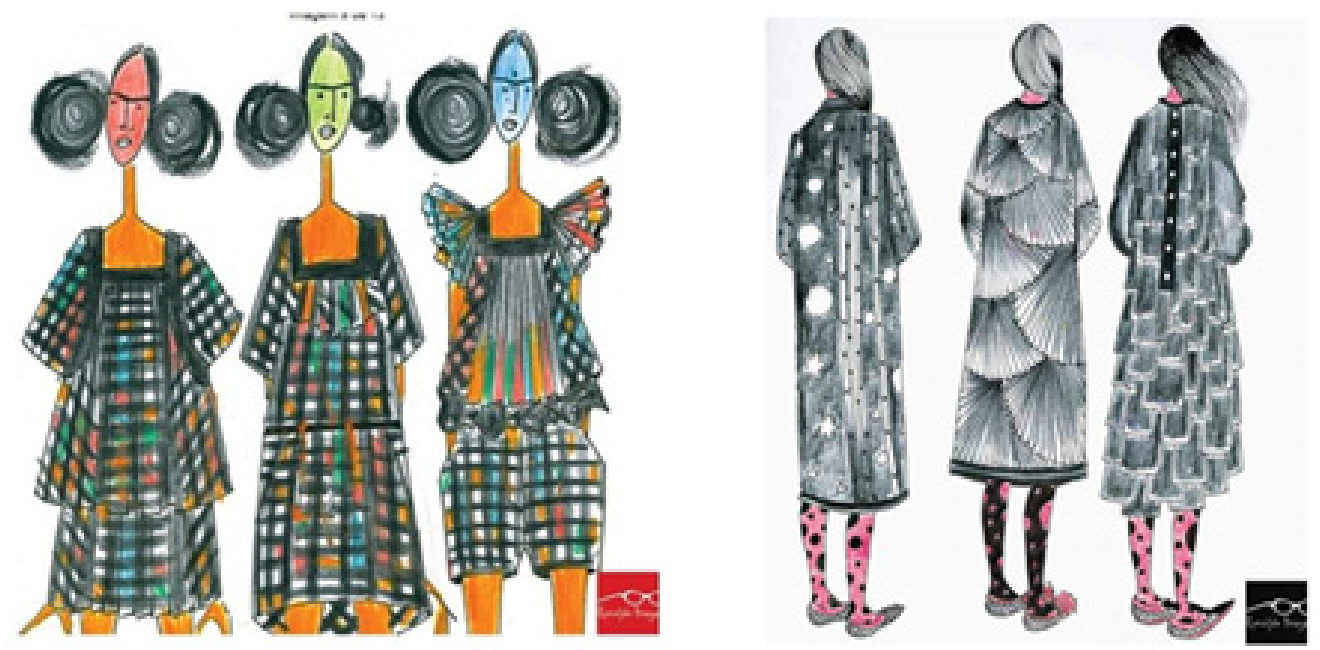

Figuras 4 e 5 - Croquis de Ronaldo Fraga - Coleção inverno 2010

Fonte: Remus (2011)

Observando os exemplos acima, é possível entender que por mais que as características estilísticas principais dos traços sejam mantidas (pois são a marca registrada do autor), é possível diferenciar o conceito que se transmite por meio da diferenciação de detalhes, como 
Paula da Silva Hatadani; Marizilda dos Santos Menezes

posição da figura humana, cores, texturas e outros códigos. Desta forma, fica claro que tratamse de croquis de coleções diferentes.

Na tabela de Montemezzo (2003) o desenho de estilo não aparece em nenhuma das etapas, porém, considerando as características até agora citadas, verifica-se que ele estaria alocado na fase de "geração de alternativas", funcionando como uma ferramenta de apresentação de projeto, complementar ao desenho de esboço, e anterior à seleção de alternativas. Por meio das afirmações encontradas na revisão bibliográfica, entendeu-se que o desenho de estilo funciona como um canal que proporciona o entendimento funcional e estético-simbólico do produto de moda. Sendo assim, são representações que, diferentemente dos esboços, possibilitam a transmissão de valores subjetivos relacionados aos produtos, sendo utilizados principalmente para uma apreciação anterior à decisão de materialização das peças.

\section{Desenho técnico de vestuário}

O desenho técnico é uma linguagem gráfica utilizada na indústria, que tem como principal objetivo orientar a fabricação de um produto. Nele, a representação de formas, dimensões e detalhamentos ocorre por meio de linhas, números, símbolos e especificações escritas e organizadas de forma precisa.

Atualmente, na maioria dos casos das áreas que o utilizam, os desenhos técnicos são elaborados por softwares gráficos, pois estes facilitam e agilizam a sua elaboração.

Para Izidoro (2009), assim como a linguagem verbal escrita exige alfabetização, a execução e a interpretação da linguagem gráfica do desenho técnico exigem treinamento específico, pois, em geral, são utilizadas figuras planas (bidimensionais) para representar formas espaciais.

Em função do seu grau de complexidade, o desenho técnico requer do designer conhecimentos específicos sobre representação gráfica, uma vez que tais fundamentos acabam sendo necessários para o desenvolvimento de um desenho adequado para o setor produtivo (SUONO, 2007, p.58).

Na prática, pode-se dizer que, para interpretar um desenho técnico, é necessário enxergar o que ainda não é visível. Esta capacidade de entender uma forma espacial a partir de uma figura plana é chamada "visão espacial". Esta visão é "um dom que, em princípio todos têm, dá a capacidade de percepção mental das formas espaciais. Perceber mentalmente uma forma espacial significa ter o sentimento da forma espacial sem estar vendo o objeto" (IZIDORO, 2009, p.5).

O desenho técnico pode possuir variáveis de linguagem diferentes, de acordo com as necessidades das áreas que o utilizam, tais como a engenharia, a arquitetura, o design de produtos e o design de moda. De acordo com Treptow (2003), o desenho técnico de vestuário pode ser denominado como "desenho planificado" ou "desenho de especificação". Morris (2006) cita também os termos "desenho esquemático" ou "desenho bidimensional" de moda. De maneira geral, entende-se o desenho técnico de vestuário como a representação do produto em que se podem identificar suas formas e pormenores. Esta é a principal característica deste tipo de representação: a preocupação com os detalhamentos do produto em suas minúcias (Figura 6): 

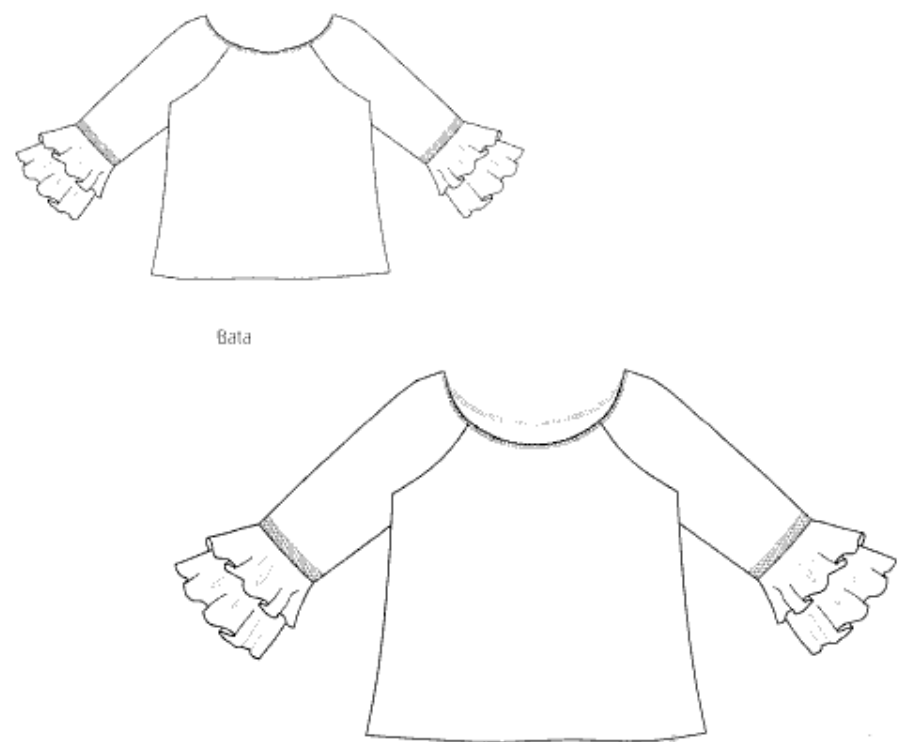

Figura 6- Exemplo de desenho técnico de vestuário

Fonte: Leite e Veloso (2004)

Além das informações dos processos em relação à modelagem, o desenho técnico de vestuário deve apresentar todos os detalhes da peça, tais como recortes, pespontos, costuras, aviamentos, forros, aplicações, bordados, estampas, entre outros. Estas particularidades, muitas vezes, podem ser indicadas por meio da linguagem verbal, com as chamadas "especificações" (Figura 7).
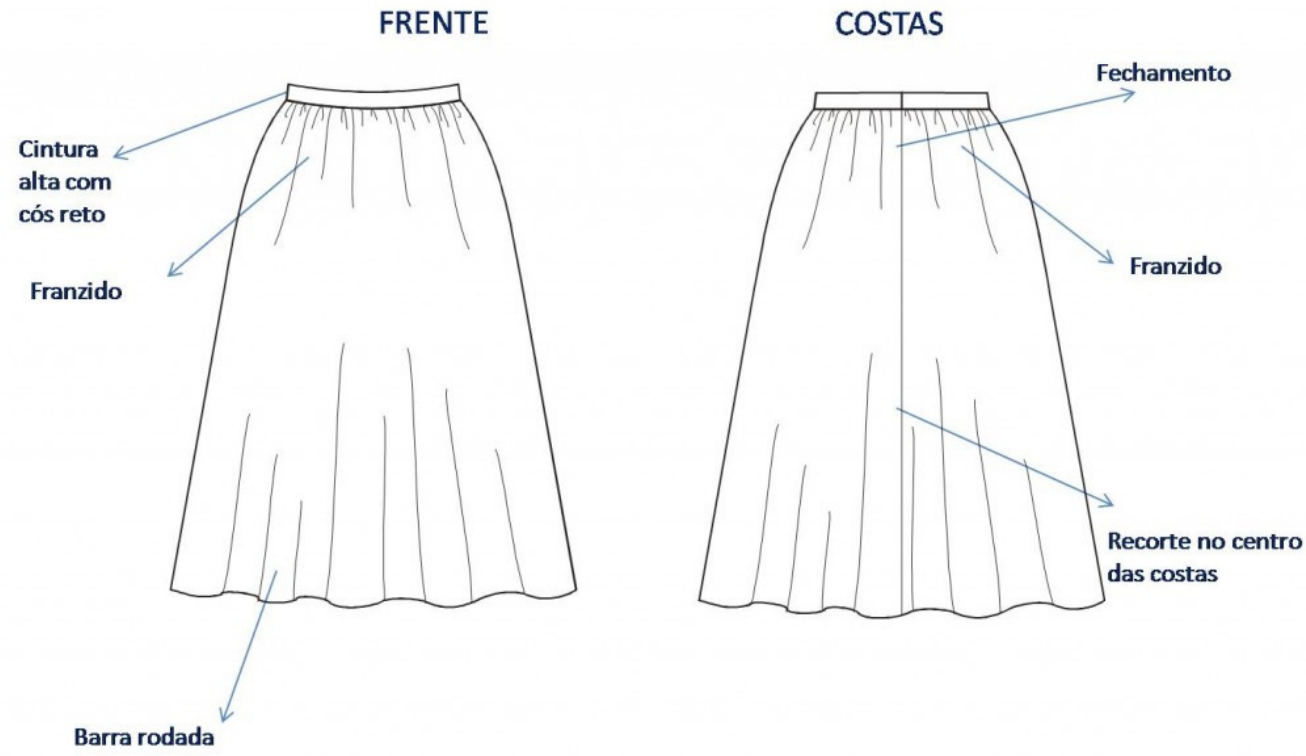

Figura 7- Desenho técnico de vestuário com especificações

Fonte: Neiva (2011)

Além das especificações, também poderão ser utilizadas cotas para indicar as principais medidas da peça. Isso facilita alguns processos, como a modelagem e o controle de qualidade (Figura 8): 


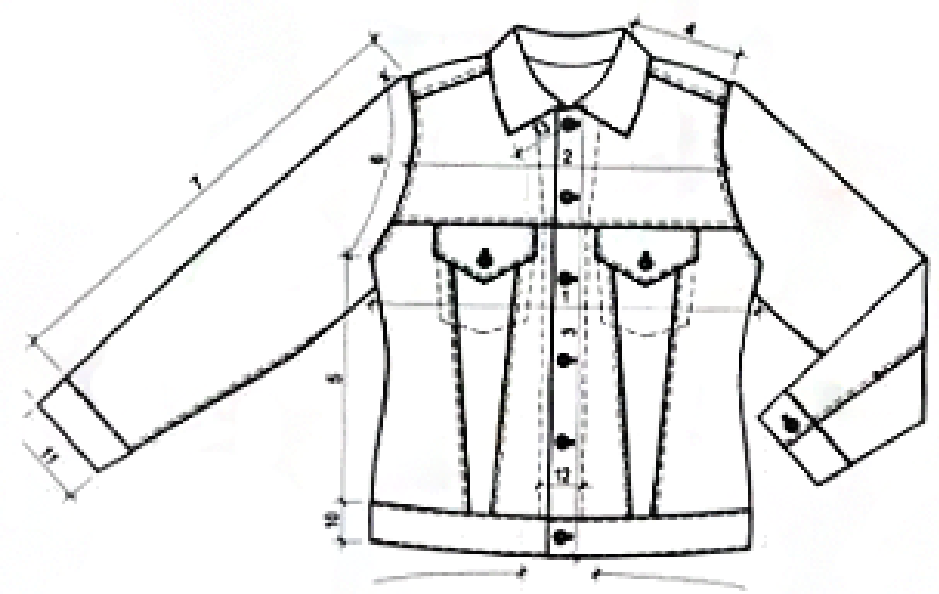

Figura 8- Desenho técnico de vestuário com cotas

Fonte: Leite e Velloso (2004)

Ao realizar o desenho técnico, o designer de moda deve ter em mente que o modelista ${ }^{2}$ e o pilotista ${ }^{3}$ deverão ser capazes de executar o produto baseando-se apenas nas instruções que ele colocou no papel. Assim, quanto mais informações de detalhes forem descritas no desenho técnico do vestuário, mais eficiente se torna o processo de materialização do produto (SUONO, 2007).

Geralmente, o desenho técnico de vestuário é inserido em uma ficha técnica, que compreende todas as especificações de materiais, aviamentos, fornecedores, grade de corte, entre outras informações, que auxiliarão a execução a idéia do designer da maneira mais precisa e eficaz quanto possível. Se a peça piloto for aprovada, o desenho técnico segue em sua respectiva ficha para a produção. No caso de haver a necessidade de repilotagem, o desenho técnico deverá ser ajustado de acordo com as mudanças realizadas.

No que se refere ao emprego do desenho técnico como ferramenta de projeto de produtos de moda, verifica-se que sua utilização ocorre a partir do momento em que as idéias já foram avaliadas e selecionadas por meio dos croquis. Na tabela de Montemezzo (2003), ele é citado na fase de "Avaliação e Elaboração", onde haverá a seleção das alternativas e o detalhamento da configuração dos produtos.

A ordem da utilização das linguagens de desenho de moda seria, por consequência: 1) esboços, 2) croquis e 3) desenhos técnicos. Após a tempestade de idéias ocorrida por meio do esboço e da avaliação e seleção dos croquis, os desenhos técnicos de cada um dos modelos aprovados são construídos para que as peças sejam pilotadas e/ou produzidas.

\section{Conclusão}

Apesar de não ser o único canal de expressão, comunicação e registro de idéias utilizado pelos designers, o desenho é a ferramenta mais utilizada atualmente na indústria do vestuário para estes fins. Por meio dele é possível comunicar informações que auxiliarão o processo de desenvolvimento e fabricação da peça, sejam elas técnicas, tais como materiais, forma, textura e acabamentos, bem como subjetivas, como atitude, humor e personalidade do público-alvo. Além disto, é uma atividade de raciocínio, sendo essencial para o processo de geração de novas idéias. 
O Desenho como Ferramenta Projetual no Design de Moda

Deve-se observar, no entanto, que em projetos de produtos de moda, assim como em projetos gráficos, de produto, ou mesmo na arquitetura e na engenharia, os fins comunicativos que presidem às intenções do emissor da mensagem gráfica contribuem para determinar as escolhas estruturais dos meios de desenho (SUONO, 2007). Entende-se, assim, que o desenho deve possuir diferentes linguagens em cada etapa do projeto em que se encontra para que os fins comunicativos específicos de cada uma delas possam ser alcançados. Se utilizado de forma coerente com estes fins, o desenho oferecerá condições para interpretações adequadas daquilo que pretende comunicar.

Mesmo que o designer tenha alto nível de conhecimentos criativos, técnicos e produtivos, a dificuldade na transmissão de idéias de projeto a outras pessoas pode provocar falhas e prejuízos significativos durante a fase de materialização do produto. Portanto, fica claro que, no que diz respeito à utilização da representação gráfica no contexto atual da indústria do vestuário, é necessária uma sistematização de conhecimento para ser aplicada na prática profissional, sendo determinante que os profissionais o utilizem no sentido de atuar na minimização de erros e a otimização dos processos tanto nas esferas produtivas quanto criativas. Sendo assim, a utilização objetiva e eficaz do desenho é fundamental para que o processo criativo seja realizado de forma plena, e também para que não ocorram problemas na decodificação das informações nas diferentes etapas de desenvolvimento de produto, e consequentemente, atrasos ou falhas na produção.

\section{Notas}

${ }^{1}$ É importante ressaltar, porém, que o desenho não é o único canal de expressão e representação possível no design de moda. A construção de painéis imagéticos, além da modelagem tridimensional (também chamada de moulage ou drapping) também são recursos passíveis de utilização com estes propósitos (PIRES, 2008).

${ }^{2} \mathrm{O}$ modelista é o profissional responsável por desenvolver os moldes (ou a modelagem), das peças de vestuário. Estes moldes são fundamentais para as demais etapas do processo produtivo.

${ }^{3} \mathrm{O}$ pilotista é o profissional responsável por costurar a peça-piloto na confecção. Esta peça servirá de guia para todas as outras costureiras.

\section{Referências}

ASSOCIAÇÃO BRASILEIRA DA INDÚSTRIA TÊXTIL (Brasil) (Comp.). Perfil do Setor. Disponível em: http://www.abit.org.br/site/navegacao.asp?id_menu=1\&id_sub=4\&idio ma =PT. Acesso em: 15 jun. 2010.

BLACKMAN, Cally. 100 años de ilustración de moda. Barcelona: Art Blume, 2007.

CROQUIS ilustrados com lápis de cor Disponível em: <http://www.clickmoda.com.br/ croquisilustrados-com-lapis-de-cor/ />. Acesso em: 01 mar. 2011.

DERDYK, Edith (Org.). Disegno. Desenho. Desígnio. São Paulo: Editora Senac SP, 2007.

DUARTE, Carla Stephania de Góis. A Ilustração de moda e o Desenho de moda. Moda Palavra: e-periódico, Florianópolis, n. 6, p.50-58, 2010. Disponível em: <http://www.ceart.udesc.br/ modapalavra/edicao6/index.php>. Acesso em: 18 dez. 2010. 
Paula da Silva Hatadani; Marizilda dos Santos Menezes

FASHION Sketches. Disponível em: <http://omegasama.deviantart.com/art/FashionSketches-126506676>. Acesso em: 01 mar. 2011.

FERREIRA, A. B. H. Dicionário Aurélio básico da língua portuguesa. Rio de Janeiro: Nova Fronteira, 1995. p. 210.

GRAGNATO, Luciana. O ensino do desenho no design de moda. In: CONGRESSO INTERNACIONAL DE PESQUISA EM DESIGN, 4., 2007, Rio de Janeiro. Anais... . Rio de Janeiro: Anped - Associação Nacional de Pesquisa em Design, 2007. p. 01 - 08.

GRAGNATO, Luciana. O desenho no design de moda. 2008. 86 f. Dissertação (Mestrado) Universidade Anhembi Morumbi, São Paulo, 2008. Disponível em: <http://www.anhembi.br/ mestradodesign/pdfs/luciana.pdf>. Acesso em: 12 nov. 2010.

IZIDORO, Nacir (Org.). Apostila de Desenho Técnico: Introdução ao estudo do Desenho Técnico. Lorena: Usp, 2009. Disponível em: <http://www.eel.usp.br/na_apostila/>. Acesso em: 03 nov. 2009.

JONES, Sue Jenkyn. Fashion design: manual do estilista. São Paulo: Cosac \& Naify, 2005.

LEITE, Adriana Sampaio; VELLOSO, Marta Delgado. Desenho técnico de roupa feminina. Rio de Janeiro: Ed. Senac Nacional, 2004.

LÖBACH, Bernd. Desenho industrial: bases para a configuração industrial. São Paulo: Ed. Edgard Blücher, 2001.

MONTEMEZZO, Maria Celeste de Fátima Sanches. Diretrizes metodológicas para o projeto de produtos de moda no âmbito acadêmico. 2003. 97f. Dissertação (Mestrado em Desenho Industrial) - Universidade Estadual Paulista. Bauru, 2003.

MORRIS, Bethan. Fashion Ilustrator: manual do ilustrador de moda. São Paulo: Cosac Naify, 2006.

NEIVA, Tania. Introdução ao desenho técnico de moda. Disponível em: <http://tanianeiva.com. $\mathrm{br} / \mathrm{p} \mathrm{p}=363>$. Acesso em: 01 mar. 2011.

PIRES, Dorotéia Baduy (Org.). Design de Moda: olhares diversos. São Paulo: Estação das Letras e Cores, 2008.

REMUS, Deisi. Os croquis do SPFW. Disponível em: <Fonte: http://www.meninait.com/>. Acesso em: 01 mar. 2011.

RIEGELMAN, Nancy. 9 heads: A Guide to Drawing Fashion. 3. ed. Los Angeles: Nine Heads Media, 2006a.

RIEGELMAN, Nancy. Colors for modern fashion: drawing fashion with colored markers. Los Angeles, Calif, 2006b.

SUONO, Celso Tetsuro. O desenho técnico do vestuário sob a ótica do profissional da área de modelagem. 2007. Dissertação (Mestrado em Desenho Industrial) - Faculdade de Arquitetura,

Projética Revista Científica de Design I Universidade Estadual de Londrina I V.2 I N.1 I Junho 2011 
O Desenho como Ferramenta Projetual no Design de Moda

Artes e Comunicação, Universidade Estadual Paulista, Bauru, 2007.

TREPTOW, Doris. Inventando moda. Santa Catarina: D. Treptow, 2003. 